\title{
DCLK1 and its interaction partners: An effective therapeutic target for colorectal cancer (Review)
}

\author{
MUTHU VIJAI, MURSALEEN BABA, SATISH RAMALINGAM and ANAND THIYAGARAJ \\ Department of Genetic Engineering, SRM Institute of Science and Technology, \\ Sri Ramaswamy Memorial (SRM) Nagar, Kattankulathur, Tamil Nadu 603203, India
}

Received December 3, 2020; Accepted June 2, 2021

DOI: $10.3892 /$ ol.2021.13111

\begin{abstract}
Doublecortin-like kinase protein 1 (DCLK1) is a microtubule-associated protein with a C-terminal serine/threonine kinase domain. Its expression was first reported in radial glial cells, where it serves an essential role in early neurogenesis, and since then, other functions of the DCLK1 protein have also been identified. Initially considered to be a marker of quiescent gastrointestinal and pancreatic stem cells, DCLK1 has recently been identified in the gastrointestinal tract as a marker of tuft cells. It has also been implicated in different types of cancer, where it regulates several vital pathways, such as Kras signaling. However, its underlying molecular mechanisms remain unclear. The present review discusses the different roles of DCLK1 and its interactions with other proteins that are homologically similar to DCLK1 to develop a novel therapeutic strategy to target cancer cells more accurately.
\end{abstract}

\section{Contents}

1. Introduction

2. Functions of DCLK1 and its role in cancer

3. DCLK1 and its interacting partners

4. Genomic evidence

5. DCLK1 as a potential small-molecule target in CRC

6. Conclusion

\section{Introduction}

Doublecortin-like kinase protein 1 (DCLK1), also known as DCAMLK1 and CLICK1, was first identified in the developing

Correspondence to: $\mathrm{Dr}$ Anand Thiyagaraj, Department of Genetic Engineering, SRM Institute of Science and Technology, Sri Ramaswamy Memorial (SRM) Nagar, B508 Bioengineering Block, Kattankulathur, Tamil Nadu 603203, India

E-mail: anandt@srmist.edu.in

Key words: doublecortin-like kinase protein 1, colorectal cancer, tuft cells, stem cell niche, cancer-initiating cells rodent brain as a brain-specific protein $(1,2)$. The DCLK1 gene is present on the 13q13.3 loci of the human chromosome 13, and codes for a member from the protein kinase superfamily and the doublecortin family (2). The DCLK1 protein contains two N-terminal doublecortin domains, which bind to microtubules and regulate their polymerization, while its $\mathrm{C}$-terminal serine/threonine-protein kinase domain, with substantial homology to $\mathrm{Ca}^{2+} /$ calmodulin-dependent protein kinase (3-6), is in between the doublecortin and the protein kinase domains, mediating multiple protein-protein interactions (7). Previous studies have reported that this protein is highly expressed in the radial glial cells and neuronal precursors, suggesting a potential role in early neurogenesis $(3,4,7)$.

DCLK1 is expressed in tuft cells of the gastrointestinal tract, and is also expressed at low levels in normal gastrointestinal cells and upregulated in several gastrointestinal malignancies (8). It is also considered a marker in cancer stem cells and cancer-initiating cells (8-11). The DCLK1 gene is speculated to serve a role in the epithelial-to-mesenchymal transition (EMT) of tumor cells by regulating the NOTCH, WNT and NFKB signaling pathways $(12,13)$. Fig. 1 illustrates the important findings of DCLK1 throughout the years. Proteins that share similar functional homology and co-expression patterns have been demonstrated to interact with each other (14). The present review discusses proteins that exhibit homology, co-expression or interaction with DCLK1. Previous studies have reported the role of DCLK1 in cancer cell self-renewal $(14,15)$. Thus, it is important to identify a novel inhibitor for DCLK1.

\section{Functions of DCLK1 and its role in cancer}

Normal function of DCLK1. DCLK1 is highly expressed in tuft cells of the gastrointestinal tract. These tuft cells are similar to taste cells and serve a chemosensory role in the small intestine and colon (16). However, their primary function is to initiate a $\mathrm{T}$ helper cell immune response against parasites (17). Tuft cells exhibit self-renewal proliferative abilities due to the expression of DCLK1 (18). The microtubule-associated protein coded by $D C L K 1$ has three major splice variants (DCLK, DCLK DCX-like and CPG16), with altered kinase activities. In addition, DCLK1 exhibits differential splicing in embryonic tissues compared with adult tissues (5). The embryonic forms of DCLK1 and DCLK-like proteins exhibit considerably higher expression in post-mitotic neurons and 
neuronal progenitor cells (radial glial cells) compared with other neuronal cells (5). The post-mitotic neurons also express DCX $(3,5)$. Furthermore, DCLK1 is highly expressed in developing mammalian brains, particualry in the neocortex and cerebellum regions, where active neurogenesis occurs. However, this expression is diminished in adults (19). DCLK1 stimulates the polymerization of tubulins while interacting with microtubulins through the tandem DCX domains, and is highly expressed in the brain (5).

Given that the temporal and spatial expression pattern of doublecortin is very similar to that of DCLK1, DCLK1 is proposed to have functions similar to that of doublecortin $(20,21)$. Thus, it may serve a role in neuronal migration, axon transport, synapse maturation and brain development (21-24). Furthermore, DCLK1 has two isoforms of varying lengths because of the epithelial changes that occur with different functions, where the shorter isoform DCLK1-S induces tumorigenesis in colorectal cancer (CRC) $(7,25,26)$. DCLK1 labels a subset of dendritic microtubules and is required for trafficking KIF1-dependent dense-core vesicles into dendrites and dendritic development (23). Although these tuft cells have significant self-renewal properties, they are not stem cells. Lineage tracing studies have demonstrated that while these cells can be a part of the reserve progenitor cells that originate from rapidly cycling or quiescent stem cells, they do not exhibit lineage tracing similar to that of the stem cells while resting or under duress (27-30). Thus, they cannot be considered quiescent or active intestinal stem cells (30). DCLK1 helps in maintaining intestinal homeostasis, along with assisting tissue regeneration (8,31-32). Thus, knocking down DCLK1 in mouse models of DDS-induced colitis followed by completely irradiating it results in the loss of DCLK1, exacerbating tissue injury and halting the tissue regeneration $(33,34)$. However, whether this is due to a deficiency in the critical tuft cell-derived niche factors or a contribution to the regenerative program by DCLK1-expressing epithelial cells remains to be investigated $(35,36)$.

DCLK1 expression in cancer. DCLK1 performs a variety of functions associated with tumorigenesis (37). The malignancy of every cancer is dependent on the metastasizing ability of a tumor; for example, the ability to move to a different organ. Angiogenesis and EMT are essential for the metastasis of cancer cells. DCLK1 regulates metastasis by controlling signaling pathways, such as the NOTCH, WNT, RTK, TGF- $\beta$ and Hedgehog pathways (37). DCLK1 is also associated with the enhancement of angiogenesis in pancreatic tumors (38). Upregulation of the DCLK1 gene downregulates microRNA (miRNA/miR)-200a expression, which in turn upregulates the expression of EMT-related transcription factors, such as ZEB1, ZEB2, SNAIL and SLUG $(25,39)$, resulting in increased angiogenesis and metastasis. Similarly, upregulation of DCLK1 also downregulates miR-143/145 expression in CRC and pancreatic cancer, which increases the expression of maintenance factors, such as NANOG, OCT4, KLF4, SOX2, RREB1 and KRAS, eventually increasing the pluripotency tumorigenicity of these types of cancer $(40,41)$. DCLK1 serves a role in various cancer functions, such as drug resistance, metastasis, secondary tumor formation and cancer recurrence (12,42-46). In addition, it helps regulate cell proliferation and invasion in Hodgkin's lymphoma (47). Overexpression of DCLK1 in primary human hepatocytes has been demonstrated to form spheroids in suspension cultures. Furthermore, these cells express high levels of $\beta$-catenin, $\alpha$-fetoprotein and SOX9, suggesting that DCLK1 can induce clonogenicity in hepatoma cells (48). Table I illustrates the role of DCLK1 in three of the most prevalent types of cancer. It also lists information on different proteins and pathways regulated by DCLK1.

DCLK1 as a cancer stem cell marker. Analyzing pre-invasive pancreatic cancer cells in mouse models has demonstrated that a subpopulation of these cancer cells are morphologically similar to the gastrointestinal tuft cells, with similar stem cell-like properties (49). It has also been reported that DCLK1 is highly expressed in these cells, serving as a potential biomarker for cancer stem cells (50). Following this discovery, it has been demonstrated that DCLK1 has similar biomarker properties in CRC and osteosarcoma (50). Immunoassay methods were performed to identify circulating cellular protein DCLK1 in CRC stem cells, proving it to be the most promising cancer stem cell marker (51-54). Thus, DCLK1 is not just a target for diagnostic purposes but is also useful in therapeutic settings $(12,42,55-59)$.

DCLK1 as a therapeutic target for cancer. Targeting DCLK1 with antibodies has helped accurately screen for CRC (60). Inhibition of DCLK1 using miR-137 and other alternate splicing methods is effective in decreasing tumorigenesis in CRC and kidney cancer (10). miR-195 targets DCLK1 and successfully reduces the pluripotency and EMT in pancreatic cancer cells (61). It is also targeted in non-small cell lung carcinoma to increase chemosensitivity of the cancer cells (62). In CRC, the sensitivity of cancer cells against chemotherapy and radiation therapy is enhanced by targeting DCLK-KRAS, using miR-15b (63). DCLS-KRAS is associated with increased tumor cell invasion in $95 \%$ of pancreatic ductal adenocarcinomas (PDAC), and is also considered an undruggable target (63). DCLK1 is associated with increased KRAS expression via the PI3K/AKT/mTOR-pathway (40). Thus, DCLK1 can potentially be targeted to decrease KRAS expression and control tumor cell invasion in PDAC.

The B cell-specific moloney murine leukemia virus insertion site 1 (Bmi-1) is a crucial regulator for the self-renewal, malignant transformation and EMT of cancer stem cells, and is upregulated in pancreatic cancer (64). DCLK1 knockdown suppresses cell proliferation, both in vitro and in vivo, and inhibits the migration and invasion capacities of pancreatic cancer cells by decreasing Bmi-1 expression; thus, suggesting a potential novel strategy to treat pancreatic cancer (64). It has been reported that DCLK1 can be selectively silenced using let-7a miRNA, which arrests tumor growth in human CRC cells (65). Recently, it was demonstrated that the co-localization of DCLK1 with autophagy-related protein p62 happens due to accumulation of DCLK1 in colon cancer cells (65). In addition, crocetinic acid targets DCLK1 in cancer cells by inhibiting the hedgehog signaling pathway in pancreatic cancer cells (65).

\section{DCLK1 and its interacting partners}

DCLK1 and DCX. DCX or doublecortin is present on the X chromosome at $\mathrm{Xq} 23$ and codes for the doublecortin family 


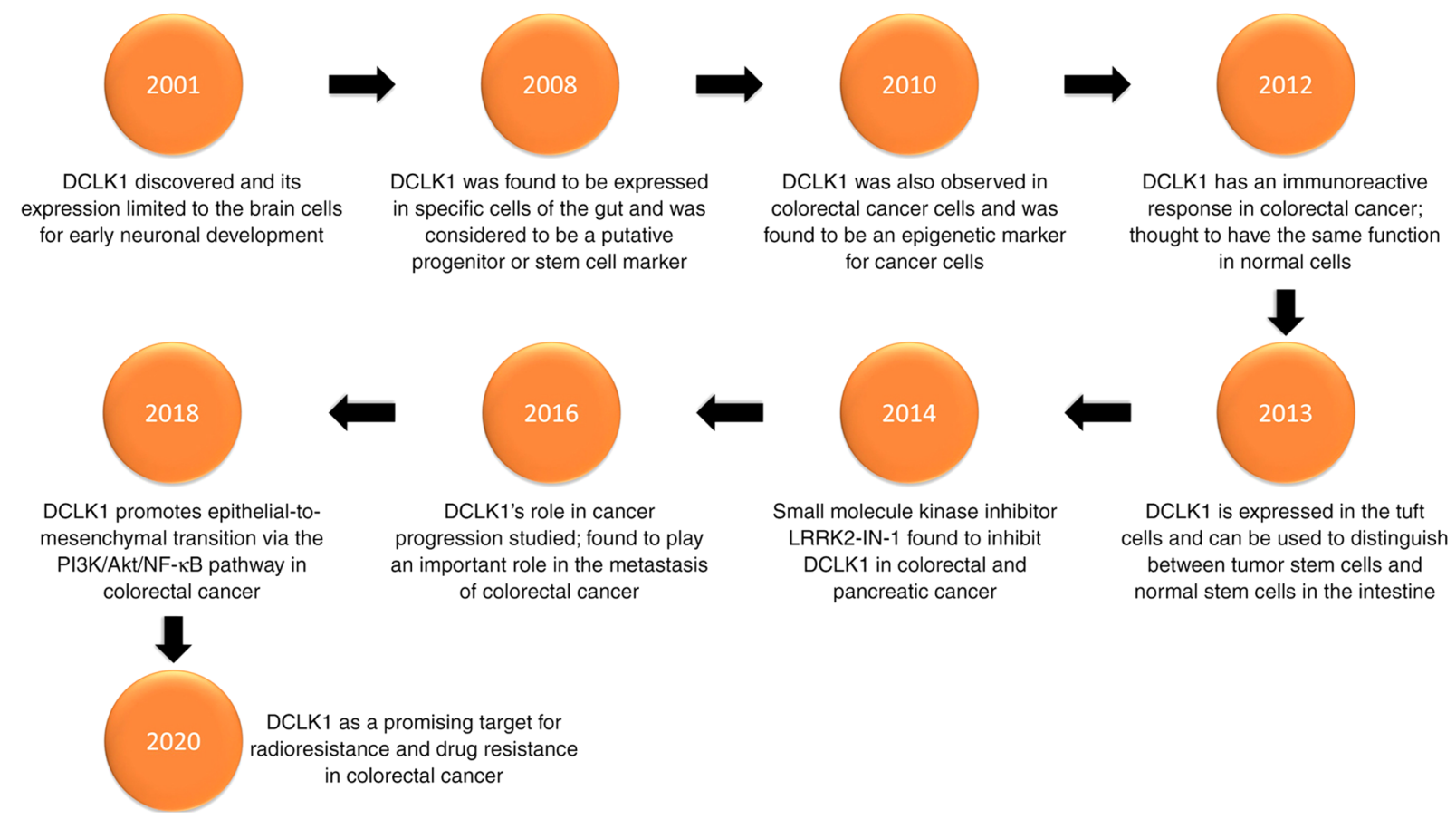

Figure 1. A timeline illustrating current breakthroughs and findings surrounding DCLK1 in colorectal cancer. DCLK1, doublecortin-like kinase protein 1; LRRk2-IN-1, leucine-rich repeat kinase 2 inhibitor 1.

of proteins $(66,67)$. DCX is a cytoplasmic microtubule-associated protein that helps stabilize microtubules (68-70). DCX and DCLK1 have protein profiles with very high homology and similar functions (71), suggesting a functional redundancy or functional equivalence. Their functional association was assessed by knocking down the DCLK gene via the RNAi strategy in rats. The results demonstrated that a dose-dependent interaction exists between DCX and DCLK1 in commissural fiber tract formation (72), which is also associated with humans, although not proven by experimental procedures $(73,74)$. In humans, DCX and DCLK1 are hypothesized to compete with each other to bind to the target proteins. This competitive binding may be a way for either protein to participate in a signaling pathway crucial for neuronal interaction before and during migration, which may be part of a calcium ion-dependent signal transduction pathway (75). Fig. 2 presents the co-expression of DCLK1 and DCX, and demonstrates the interaction between them.

$D C L K 1$ and $A N K 2$. The ANK2 gene codes for a family of proteins that play key roles in cellular functions, such as cell motility, activation, proliferation, cell-cell contact signaling and the maintenance of specialized membrane domains (76). In humans, the $A N K 2$ and DCLK1 genes are implicated in co-expression networks, with an RNA co-expression score of 0.305 (Fig. 2) (71). ANK2, similarly to DCLK1, serves a role in the progression of gastric cancer. While DCLK1 plays a role in promoting the EMT process of gastric cancer and helps in lymphovascular invasion $(77,78)$, ANK2 serves a role in promoting the proliferation of the cancer cells. Targeting and silencing ANK2 using miR-647 inhibits the proliferation of gastric cancer cells $(79,80)$. Notably, while trying to identify the genes regulating normal hearing, an audiometric pattern has been observed in the expression of the genes. Differences between different mice genotypes have also been observed, supporting ANK2's role in hearing function (81-83).

DCLK1 and MSII. The MSII gene, also known as Musashi RNA binding protein 1 , encodes a protein containing two conserved tandem RNA recognition motifs (83). Similar proteins in other species function as RNA-binding proteins, playing central roles in post-transcriptional gene regulation (84). The MSI1 protein is associated with various factors, including the grade of the malignancy, proliferative activity in glioma melanomas, esophageal cancer and colon cancer (85-87). The MSII gene was initially identified as a neuronal stem cell marker, which can affect cell cycle regulation, proliferation and apoptosis by suppressing the expression of certain mRNAs and other genes $(88,89)$. The MSII gene, similar to the DCLK1 gene, is also an intestinal stem cell marker, which is expressed alongside DLCK1 in gastric cancer cells (90). Targeting and silencing of the MSII gene activates certain tumor-suppressing mRNAs, inhibiting the growth of cancers $(88,91-93)$. The Musashi RNA binding protein activates the WNT and NOTCH signaling pathways to regulate proliferation (91). In humans, the MSI1 and DCLK1 genes are a part of multiple co-expression networks (71), and it has been reported that DCLK1 is often expressed in cells that also express the MSII gene, namely the long-lived tuft cells (94). This suggests that MSI1 may interact with DCLK1 to help tumor progression.

TNIK and CALM1 proteins. According to GeneMANIA (https://genemania.org), DCLK1 physically interacts with TRAF2 and NCK interacting Kinase (TNIK) and calmodulin (CALM1) proteins (95). The TNIK protein is an activator of the WNT signaling pathway, which is regulated in several types of cancer, including CRC (96). Thus, DCLK1 can directly or 
Table I. Comparing three of the most prevalent types of cancer and the functions of DCLK1.

\begin{tabular}{|c|c|c|c|}
\hline Characteristic & Colorectal cancer & Pancreatic cancer & Gastric cancer \\
\hline Role of DCLK1 & Promotes EMT & $\begin{array}{l}\text { Promotes stem cell pluripotency, } \\
\text { angiogenesis and EMT }\end{array}$ & $\begin{array}{l}\text { Cancer initiation, progression } \\
\text { and EMT }\end{array}$ \\
\hline Proteins regulated by DCLK1 & $\begin{array}{l}\text { P65 subunit of the NF-kB } \\
\text { transcription factor; } \mathrm{Sp} 1 \\
\text { transcription factor }\end{array}$ & $\begin{array}{l}\text { Pluripotency factors, such as } \\
\text { OCT4, SOX2, c-MYC, LIN28, } \\
\text { NANOG and KLF4 }\end{array}$ & $\begin{array}{l}\text { P65 subunit of the NF- } \mathrm{NB} \\
\text { transcription factor; Sp1 } \\
\text { transcription factor }\end{array}$ \\
\hline Pathways regulated by DCLK1 & PI3K/Akt pathway & NOTCH signalling pathway & $\begin{array}{l}\text { NOTCH, NF- } \kappa \mathrm{B}, \mathrm{KRAS} \text {, and } \\
\text { WNT molecular signalling } \\
\text { pathways }\end{array}$ \\
\hline Therapeutic treatment & $\begin{array}{l}\text { Targeting DCLK1 with } \\
\text { inhibitors, such as } \\
\text { LRRk2-IN-1 small } \\
\text { molecule }\end{array}$ & $\begin{array}{l}\text { Downregulation of DCLK1 } \\
\text { upregulates tumor suppressor } \\
\text { mRNAs }\end{array}$ & $\begin{array}{l}\text { Targeting DCLK1 with } \\
\text { inhibitors, such as LRRk2-IN-1 } \\
\text { small molecule }\end{array}$ \\
\hline
\end{tabular}

DCLK1, doublecortin-like kinase protein 1; EMT, epithelial-to-mesenchymal transition; NF- $\kappa$ B, nuclear factor $\kappa$ light chain enhancer of activated B cells; OCT4, octamer-binding transcription factor 4; SOX2, SRY (sex determining region Y)-box 2; KLF4, Kruppel-like factor 4; LRRk2-In-1, Leucine-rich repeat kinase 2 Inhibitor 1.
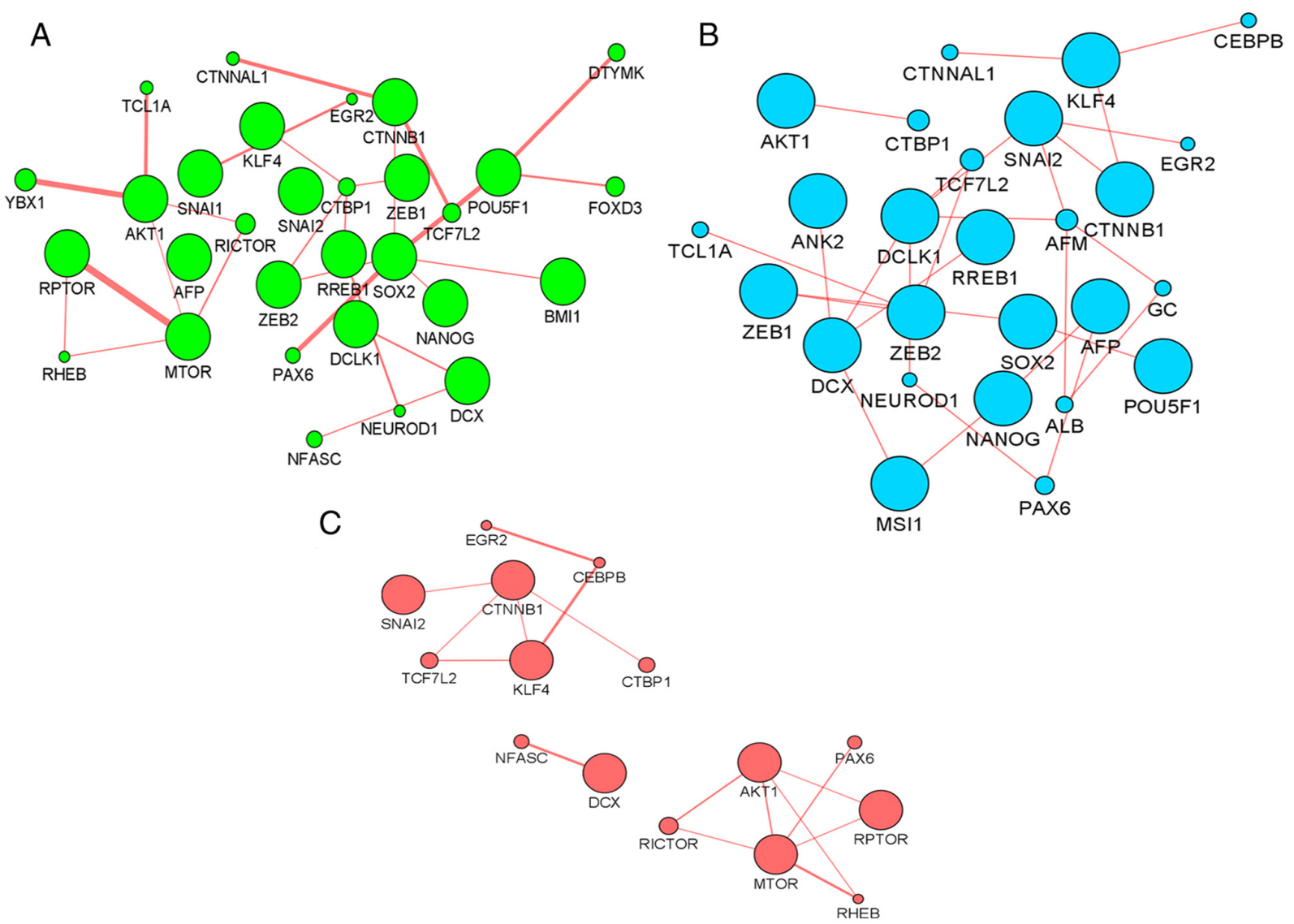

Figure 2. Networks generated using Cytoscape software (v.3.8.2; on Java 11.0.6 by AdoptOpenJDK) to elucidate the interaction between DCLK1 and different proteins. (A) Co-expression patterns, (B) consolidated pathways and (C) physical interactions. Circles represent proteins; DCLK1, doublecortin-like kinase protein 1.

indirectly interact with TNIK to regulate the WNT signaling pathway. The CALM1 protein mediates the control of various enzymes, ion channels, aquaporins and other proteins via calcium-binding (97). The C-terminal of the DCLK1 protein has a serine/threonine-protein kinase domain, which exhibits substantial homology to $\mathrm{Ca}^{2+} /$ calmodulin-dependent protein kinase, making it possible for the CALM1 protein to regulate DCLK1 through its domain (Fig. 2). 


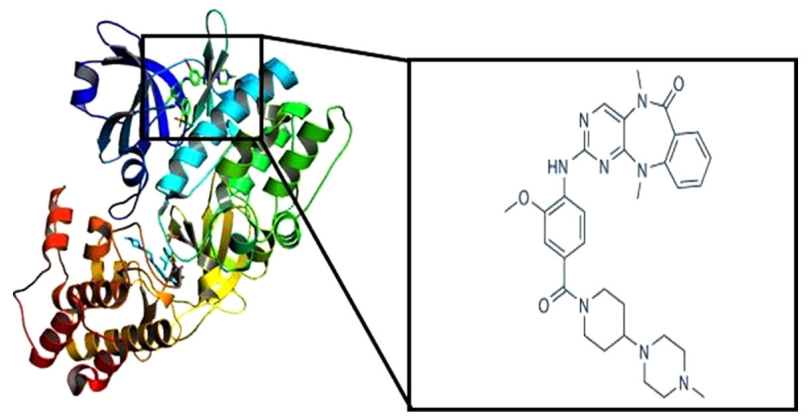

Figure 3. Doublecortin-like kinase protein 1 protein bound to the kinase domain of small molecule LRRk2-IN-1 (left). Chemical structure of LRRk2-IN-1 (right). LRRk2-IN-1, leucine-rich repeat kinase 2 inhibitor 1.

\section{Genomic evidence}

In 2015, scientists performed a series of genomic experiments to identify the protein interactions, where high-throughput affinity purification mass spectroscopy was performed to identify the interacting partners of 2,594 proteins in HEK293T cells (75). The resulting network (BioPlex) revealed 23,744 interactions among 7,668 proteins, with $86 \%$ interactions previously undocumented (75). In 2017, the same scientists released Bioplex 2.0, which contained interacting partners of $25 \%$ of protein-coding genes, with $>29,000$ previously unknown co-associations (76). According to the Bioplex 2.0 network, the highest-scoring interacting proteins with DCLK1 were cell division cycle associated 8 (CDCA8), deoxyguanosine kinase (DGUOK), filamin binding LIM protein 1 (FBLIM1), HCLS1-associated protein X1 (HAX1) and nuclear FMR1 interacting protein (NUFIP1). All these five proteins were found to be molecular targets of DCLK1. CDCA8 plays roles in mitosis and cell division, and also helps in chromatin-induced microtubule stabilization (98). Being a microtubule-associated protein, DCLK1 may be associated with CDCA8. Overexpression of CDCA8 promotes proliferation of bladder cancer cells (98). DGUOK has a similar kinase function to DCLK1 and can regulate cancer cell stemness (99). FBLIM1 helps in cell adhesion and motility (100), and when overexpressed in glioma, it increases cancer cell migration, which can be induced by DCLK1 as it plays a role in angiogenesis and metastasis (100). HAX1 is a potential oncogene for hypopharyngeal carcinoma, which increases cancer cell proliferation and migration (101). The NUFIP1 protein interacts with the tumor suppressor protein, BRCA (102). Notably, proteins with high scores have an implicated role in different types of cancer.

\section{DCLK1 as a potential small-molecule target in CRC}

The aforementioned profile insights of the DCLK1 gene prove that they are key components of CRC pathogenesis (13). Targeting the DCLK1 kinase domain to inhibit its function may be an effective strategy for treating CRC (52). The interaction profile of DCLK1, along with its co-expressing genes, seem to share a strong homology $(52,103)$; thus, there is a requirement for a specific small molecule to inhibit DCLK1. It has been demonstrated that the inhibitor of Leucine-rich repeat kinase 2
(LRRk) protein, LRRk2-IN-1, a key regulator in Alzheimer's disease, inhibits DCLK1 in vitro (103). Recently, an analog of LRRk2-IN-1 was designed and successfully tested as a DCLK1 inhibitor (Fig. 3) (103). Although these small molecules are effective, there is ambiguity regarding their non-specificity to DCLK1, since DCLK1 also has strong homology to other interaction partners $(103,104)$. Thus, 3D pharmacophore-based strategy for high throughput virtual screening (HTVS) can be applied against a natural compound databases (105). These databases have millions of compounds that are commercially available. Thus, HTVS combined with molecular docking and molecular dynamics studies may provide insights into secondary structure changes induced by small-molecule binding. Such computational methods combined with in vitro validation can help identify effective inhibitors for DCLK1 (105). Furthermore, building a pharmacophore model from molecular dynamics simulations of LRRk2-IN-1, which is a recent approach in identifying potential small moleculae inhibitors, can be an effective strategy in designing a novel small molecule inhibitor for DCLK1 (106). A computational quantum mechanical modeling method, such as density functional theory, can be used to study the electronegativity of these small molecules interacting with DCLK1 (107-109).

\section{Conclusion}

DCLK1 was initially identified for its function in neuronal development, but has recently been implicated as an epigenetic marker in tuft cells of the intestine, and also in tumorigenesis. DCLK1 interacts with several proteins and regulates various pathways to perform functions, ranging from cancer initiation to metastasis. Understanding the pathways and their interactions with DCLK1 is important to develop effective treatment strategies for different types of cancer. Currently, targeting and silencing DCLK1 using small molecule kinase inhibitors is a good therapeutic strategy for treating colorectal cancer. However, this strategy is non-specific and thus is inefficient. In addition, the underlying molecular mechanisms of DCLK1 remain unclear. Proteins with a similar homology and co-expression pattern to DCLK1 can be used to determine the exact molecular mechanism of the protein. With the development of techniques, such as next-generation 3D pharmacophore modeling, the profiles of DCLK1 and its interaction partners can be extensively investigated (110-114). Understanding the underlying molecular mechanisms of DCLK1 is important in identifying small molecules that can effectively bind and inhibit DCLK1. In addition, targeting the interacting partners of DCLK1 may be an effective treatment strategy.

\section{Acknowledgements}

Not applicable.

\section{Funding}

No funding was received.

\section{Availability of data and materials}

Not applicable. 


\section{Authors' contributions}

MV drafted the initial manuscript. MB generated ad interpreted the images and contributed to a concept that deals with the interaction of DCLK1 protein. SR critically reviewed the manuscript for important intellectual content. AT conceptualized the hypothesis and performed a critical review of the paper. Data authentication is not applicable. All authors have read and approved the final manuscript.

\section{Ethics approval and consent to participate}

Not applicable.

\section{Patient consent for publication}

Not applicable.

\section{Competing interests}

The authors declare that they have no competing interests.

\section{References}

1. The Human Protein ATLAS: DCLK1. Human Protein ATLAS Summary. https://www.proteinatlas. org/ENSG00000133083-DCLK1. Accessed June 8, 2020.

2. National Center for Biotechnology Information (NCBI): DCLK1 doublecortin like kinase 1 [Homo sapiens (human)]. NCBI, Bethesda, MD, 2020. https://www.ncbi.nlm.nih.gov/gene/9201. Accessed June 8, 2020.

3. Vreugdenhil E, Kolk SM, Boekhoorn K, Fitzsimons CP, Schaaf M, Schouten T, Sarabdjitsingh A, Sibug R and Lucassen PJ: Doublecortin-like, a microtubule-associated protein expressed in radial glia, is crucial for neuronal precursor division and radial process stability. Eur J Neurosci 25: 635-648, 2007.

4. Walker TL, Yasuda T, Adams DJ and Bartlett PF: The doublecortin-expressing population in the developing and adult brain contains multipotential precursors in addition to neuronal-lineage cells. J Neurosci 27: 3734-3742, 2007.

5. Lin PT, Gleeson JG, Corbo JC, Flanagan L and Walsh CA: DCAMKL1 encodes a protein kinase with homology to doublecortin that regulates microtubule polymerization. J Neurosci 20 : 9152-9161, 2000

6. Matsumoto N, Pilz DT and Ledbetter DH: Genomic structure, chromosomal mapping, and expression pattern of human DCAMKL1 (KIAA0369), a homologue of DCX (XLIS). Genomics 56: 179-183, 1999.

7. Burgess HA and Reiner O: Alternative splice variants of doublecortin-like kinase are differentially expressed and have different kinase activities. J Biol Chem 277: 17696-17705, 2002.

8. Hirshoren N, Cohen J, Neuman T, Weinberger JM and Eliashar R: DCLK1 expression in gastrointestinal stem cells and neoplasia. J Cancer Ther Res 1: 12, 2012.

9. Liu H, Wen T, Zhou Y, Fan X, Du T, Gao T, Li L, Liu J, Yang L, Yao J, et al: DCLK1 plays a metastatic-promoting role in human breast cancer cells. Biomed Res Int 2019: 1061979, 2019.

10. Sakaguchi M, Hisamori S, Oshima N, Sato F, Shimono Y and Sakai Y: MIR-137 regulates the tumorigenicity of colon cancer stem cells through the inhibition of DCLK1. Mol Cancer Res 14: 354-362, 2016.

11. Chandrakesan P, Yao J, Qu D, May R, Weygant N, Ge Y, Ali N, Sureban SM, Gude M, Vega K, et al: Dclk1, a tumor stem cell marker, regulates pro-survival signaling and self-renewal of intestinal tumor cells. Mol Cancer 16: 30, 2017.

12. Chandrakesan P, Panneerselvam J, Qu D, Weygant N, May R, Bronze MS and Houchen CW: Regulatory Roles of Dclk1 in epithelial mesenchymal transition and cancer stem cells. J Carcinog Mutagen 7: 257, 2016.

13. Liu W, Wang S, Sun Q, Yang Z, Liu Mand Tang H: DCLK1 promotes epithelial-mesenchymal transition via the PI3K/Akt/NF- $\kappa \mathrm{B}$ pathway in colorectal cancer. Int J Cancer 142: 2068-2079, 2018.
14. Sureban SM, May R, Ramalingam S, Subramaniam D, Natarajan G, Anant S and Houchen CW: Selective blockade of DCAMKL-1 results in tumor growth arrest by a Let-7a MicroRNA-dependent mechanism. Gastroenterology 137: 649-59, 659.e1-2, 2009.

15. Roy BC, Ahmed I, Ramalingam S, Jala V, Haribabu B, Ramamoorthy P, Ashcraft J, Valentino J, Anant S, Sampath V and Umar S: Co-localization of autophagy-related protein p62 with cancer stem cell marker dclk1 may hamper dclk1's elimination during colon cancer development and progression. Oncotarget 10: 2340-2354, 2019.

16. Gerbe F, Legraverend C and Jay P: The intestinal epithelium tuft cells: Specification and function. Cell Mol Life Sci. 69: 2907-2917, 2012

17. DelGiorno KE, Naeem RF, Fang L, Chung CY, Ramos C, Luhtala N, O'Connor C, Hunter T, Manor U and Wahl GM: Tuft cell formation reflects epithelial plasticity in pancreatic injury: Implications for modeling human pancreatitis. Front Physiol 11: 88, 2020.

18. Ting HA and von Moltke J: The Immune function of tuft cells at gut mucosal surfaces and beyond. J Immunol 202: 1321-1329, 2019.

19. Shu T, Tseng HC, Sapir T, Stern P, Zhou Y, Sanada K, Fischer A, Coquelle FM, Reiner O and Tsai LH: Doublecortin-like kinase controls neurogenesis by regulating mitotic spindles and $\mathrm{M}$ phase progression. Neuron 49: 25-39, 2006.

20. Liu JS, Schubert CR, Fu X, Fourniol FJ, Jaiswal JK, Houdusse A, Stultz CM, Moores CA and Walsh CA: Molecular basis for specific regulation of neuronal kinesin-3 motors by doublecortin family proteins. Mol Cell 47: 707-721, 2012.

21. Shin E, Kashiwagi Y, Kuriu T, Iwasaki H, Tanaka T, Koizumi H, Gleeson JG and Okabe S: Doublecortin-like kinase enhances dendritic remodelling and negatively regulates synapse maturation. Nat Commun 4: 1440, 2013.

22. Qin J, Mizuguchi M, Itoh M and Takashima S: A novel migration-related gene product, doublecortin, in neuronal migration disorder of fetuses and infants with Zellweger syndrome. Acta Neuropathol 100: 168-173, 2000.

23. Lipka J, Kapitein LC, Jaworski J and Hoogenraad CC: Microtubule-binding protein doublecortin-like kinase 1(DCLK1) guides kinesin-3-mediated cargo transport to dendrites. EMBO J 35: 302-318, 2016.

24. Lu Y, Maruyama J, Kuwata K, Fukuda H, Iwasa H, Arimoto-MatsuzakiK, Sugimura Hand Hata Y: Doublecortin-like kinase 1 compromises DNA repair and induces chromosomal instability. Biochem Biophys Reports 16: 130-137, 2018.

25. O'Connell MR, Sarkar S, Luthra GK, Okugawa Y, Toiyama Y, Gajjar AH, Qiu S, Goel A and Singh P: Epigenetic changes and alternate promoter usage by human colon cancers for expressing DCLK1-isoforms: Clinical Implications. Sci Rep 5: 14983, 2015.

26. Singh P, O'Connell M and Shubhashish S: Epigenetic regulation of human DCLK-1 gene during coloncarcinogenesis: Clinical and mechanistic implications. Stem Cell Investig 3: 51, 2016.

27. Barker $\mathrm{N}$ and Clevers $\mathrm{H}$ : Lineage tracing in the intestinal epithelium. Curr Protoc Stem Cell Biol Chapter 5: Unit5A.4, 2010.

28. Kretzschmar K and Watt FM: Lineage tracing. Cell 148: 33-45, 2012.

29. Simons BD and Clevers H: Stem cell self-renewal in intestinal crypt. Exp Cell Res 31: 2719-2724, 2011.

30. Tan DW and Barker N: Intestinal stem cells and their defining niche. Curr Top Dev Biol 107: 77-107, 2014.

31. Westphalen CB, Asfaha S, Hayakawa Y, Takemoto Y, Lukin DJ, Nuber AH, Brandtner A, Setlik W, Remotti H, Muley A, et al: Long-lived intestinal tuft cells serve as colon cancer-initiating cells. J Clin Invest 124: 1283-1295, 2014.

32. May R, Qu D, Weygant N, Chandrakesan P, Ali N, Lightfoot SA, Li L, Sureban SM and Houchen CW: Brief report: Dclk1 deletion in tuft cells results in impaired epithelial repair after radiation injury. Stem Cells 32: 822-827, 2014.

33. Qu D, Weygant N, May R, Chandrakesan P, Madhoun M, Ali N, Sureban SM, An G, Schlosser MJ and Houchen CW: Ablation of doublecortin-like kinase 1 in the colonic epithelium exacerbates dextran sulfate sodium-induced colitis. PLoS One 10: e0134212, 2015.

34. Westphalen CB, Takemoto Y, Tanaka T, Macchini M, Jiang Z Renz BW, Chen X, Ormanns S, Nagar K, Tailor Y, et al: Dclk1 defines quiescent pancreatic progenitors that promote injury-induced regeneration and tumorigenesis. Cell Stem Cell 18: 441-455, 2016. 
35. Middelhoff M, Westphalen CB, Hayakawa Y, Yan KS Gershon MD, Wang TC and Quante M: Dclk1-expressing tuft cells: Critical modulators of the intestinal niche? Am J Physiol Gastrointest Liver Physiol 313: G285-G299, 2017.

36. Chandrakesan P, May R, Weygant N, Qu D, Berry WL, Sureban SM, Ali N, Rao C, Huycke M, Bronze MS and Houchen CW: Intestinal tuft cells regulate the ATM mediated DNA Damage response via Dclk1 dependent mechanism for crypt restitution following radiation injury. Sci Rep 6: 37667 , 2016.

37. Sureban SM, May R, Weygant N, Qu D, Chandrakesan P, Bannerman-Menson E, Ali N, Pantazis P, Westphalen CB, Wang TC and Houchen CW: XMD8-92 inhibits pancreatic tumor xenograft growth via a DCLK1-dependent mechanism. Cancer Lett 351: 151-161, 2014.

38. Gagliardi G, Goswami M, Passera R and Bellows CF: DCLK1 immunoreactivity in colorectal neoplasia. Clin Exp Gastroenterol 5: 35-42, 2012.

39. Qu D, Weygant N, Yao J, Chandrakesan P, Berry WL, May R, Pitts K, Husain S, Lightfoot S, Li M, et al: Overexpression of DCLK1-AL increases tumor cell invasion, drug resistance, and KRAS activation and can be targeted to inhibit tumorigenesis in pancreatic cancer. J Oncol 2019: 6402925, 2019.

40. Powrózek T, Krawczyk P, Nicoś M, Kuźnar-Kamińska B Batura-Gabryel H and Milanowski J: Methylation of the DCLK1 promoter region in circulating free DNA and its prognostic value in lung cancer patients. Clin Transl Oncol 18: 398-404, 2016.

41. Whorton J, Sureban SM, May R, Qu D, Lightfoot SA, Madhoun M, Johnson M, Tierney WM, Maple JT, Vega KJ and Houchen CW: DCLK1 is detectable in plasma of patients with barrett's esophagus and esophageal adenocarcinoma. Dig Dis Sci 60: 509-513, 2015 .

42. Wu X, Qu D, Weygant N, Peng J and Houchen CW: Cancer stem cell marker DCLK1 correlates with tumorigenic immune infiltrates in the colon and gastric adenocarcinoma microenvironments. Cancers (Basel) 12: 274, 2020

43. Ito H, Tanaka S, Akiyama Y, Shimada S, Adikrisna R, Matsumura S, Aihara A, Mitsunori Y, Ban D, Ochiai T, et al: Dominant expression of DCLK1 in human pancreatic cancer stem cells accelerates tumor invasion and metastasis. PLoS One 11: e0146564, 2016.

44. Gao T, Wang M, Xu L, Wen T, Liu J and An G: DCLK1 is up-regulated and associated with metastasis and prognosis in colorectal cancer. J Cancer Res Clin Oncol 142: 2131-2140, 2016.

45. Sureban SM, May R, Qu D, Weygant N, Chandrakesan P, Ali N, Lightfoot SA, Pantazis P, Rao CV, Postier RG and Houchen CW: DCLK1 regulates pluripotency and angiogenic factors via microRNA-dependent mechanisms in pancreatic cancer. PLoS One 8: e73940, 2013.

46. Ge Y, Weygant N, Qu D, May R, Berry WL, Yao J, Chandrakesan P Zheng W, Zhao L, Zhao KL, et al: Alternative splice variants of DCLK1 mark cancer stem cells, promote self-renewal and drug-resistance, and can be targeted to inhibit tumorigenesis in kidney cancer. Int J Cancer 143: 1162-1175, 2018.

47. Fan CB, Yan XH, Tian M, Zhang S, Liu JL, Sheng YX, Dong L and Zhang WL: Long non-coding RNA NEAT1 regulates Hodgkin's lymphoma cell proliferation and invasion via miR-448 mediated regulation of DCLK1. Eur Rev Med Pharmacol Sci 24 6219-6227, 2020

48. Ali N, Nguyen CB, Chandrakesan P, Wolf RF, Qu D, May R, Goretsky T, Fazili J, Barrett TA, Li M, et al: Doublecortin-like kinase 1 promotes hepatocyte clonogenicity and oncogenic programming via non-canonical $\beta$-catenin-dependent mechanism. Sci Rep 10: 10578, 2020.

49. Gzil A, Zarebska I, Bursiewicz W, Antosik P, Grzanka D and Szylberg $€$ : Markers of pancreatic cancer stem cells and their clinical and therapeutic implications. Mol Biol Rep 46 : 6629-6645, 2019.

50. Subramaniam D, Angulo P, Ponnurangam S, Dandawate P, Ramamoorthy P, Srinivasan P, Iwakuma T, Weir SJ, Chastain K and Anant S: Suppressing STAT5 signaling affects osteosarcoma growth and stemness. Cell Death Dis 11: 149, 2020.

51. Fesler A, Liu H and Ju J: Modified miR-15a has therapeutic potential for improving treatment of advanced stage colorecta cancer through inhibition of BCL2, BMI, YAP1 and DCLK1. Oncotarget 9: 2367-2383, 2018.

52. Kantara C, O'Connell M, Sarkar S, Moya S, Ullrich R and Singh P: Curcumin promotes autophagic survival of a subset of colon cancer stem cells, which are ablated by DCLK1-siRNA. Cancer Res 74: 2487-2498, 2014
53. Sarkar S, O'Connell MR, Okugawa Y, Lee BS, Toiyama Y, Kusunoki M, Daboval RD, Goel A and Singh P: FOXD3 regulates csc marker, dclk1-s, and invasive potential: Prognostic implications in colon cancer. Mol Cancer Res 15: 1678-1691, 2017.

54. Weygant N, Ge Y, Qu D, Kaddis JS, Berry WL, May R, Chandrakesan P, Bannerman-Menson E, Vega KJ, Tomasek JJ, et al: Survival of patients with gastrointestinal cancers can be predicted by a surrogate microRNA signature for cancer stem-like cells marked by DCLK1 kinase. Cancer Res 76: 4090-4099, 2016.

55. Mirzaei A, Madjd Z, Kadijani AA, Tavakoli-Yaraki M, Modarresi MH, Verdi J, Akbari A and Tavoosidana G: Evaluation of circulating cellular DCLK1 protein, as the most promising colorectal cancer stem cell marker, using immunoassay based methods. Cancer Biomark 17: 301-311, 2016.

56. Bailey JM, Alsina J, Rasheed ZA, McAllister FM, Fu YY, Plentz R, Zhang H, Pasricha PJ, Bardeesy N, Matsui W, et al: DCLK1 marks a morphologically distinct subpopulation of cells with stem cell properties in pre-invasive pancreatic cancer. Gastroenterology 146: 245-256, 2014.

57. Vedeld HM, Skotheim RI, Lothe RA and Lind GE: The recently suggested intestinal cancer stem cell marker DCLK1 is an epigenetic biomarker for colorectal cancer. Epigenetics 9: 346-350, 2014.

58. Mirzaei A, Tavoosidana G, Modarressi MH, Rad AA, Fazeli MS Shirkoohi R, Tavakoli-Yaraki M and Madjd Z: Upregulation of circulating cancer stem cell marker, DCLK1 but not Lgr5, in chemoradiotherapy-treated colorectal cancer patients. Tumor Biol 36: 4801-4810, 2015.

59. Sarkar S, Popov VL, O'Connell MR, Stevenson HL, Lee BS, Obeid RA, Luthra GK and Singh P: A novel antibody against cancer stem cell biomarker, DCLK1-S, is potentially useful for assessing colon cancer risk after screening colonoscopy. Lab Invest 97: 1245-1261, 2017.

60. Krishnamachary B, Subramaniam D, Dandawate $P$ Ponnurangam S, Srinivasan P, Ramamoorthy P, Umar S, Thomas SM, Dhar A, Septer S, et al: Targeting transcription factor TCF4 by $\gamma$-Mangostin, a natural xanthone. Oncotarget 10: 5576-5591, 2019

61. Zhou B, Sun C, Hu X, Zhan H, Zou H, Feng Y, Qiu F, Zhang S, Wu L and Zhang B: MicroRNA-195 suppresses the progression of pancreatic cancer by targeting DCLK1. Cell Physiol Biochem 44: 1867-1881, 2017.

62. Deng H, Qianqian G, Ting J and Aimin Y: miR-539 enhances chemosensitivity to cisplatin in non-small cell lung cancer by targeting DCLK1. Biomed Pharmacother 106: 1072-1081, 2018.

63. Ji D, Zhan T, Li M, Yao Y, Jia J, Yi H, Qiao M, Xia J, Zhang Z, Ding $\mathrm{H}$, et al: Enhancement of sensitivity to chemo/radiation therapy by using miR-15b against DCLK1 in colorectal cancer. Stem Cell Reports 11: 1506-1522, 2018

64. Li J, Wang Y, Ge J, Li W, Yin L, Zhao Z, Liu S, Qin H, Yang J, Wang L, et al: Doublecortin-like kinase 1 (DCLK1) regulates B cell-specific moloney murine leukemia virus insertion site 1 (Bmi-1) and is associated with metastasis and prognosis in pancreatic cancer. Cell Physiol Biochem 51: 262-277, 2018.

65. Rangarajan P, Subramaniam D, Paul S, Kwatra D, Palaniyandi K, Islam S, Harihar S, Ramalingam S, Gutheil W, Putty S, et al: Crocetinic acid inhibits hedgehog signaling to inhibit pancreatic cancer stem cells. Oncotarget 6: 27661-27673, 2015.

66. National Institutes of Health (NIH): DCX gene doublecortin-Genetics Home Reference. NIH, Bethesda, MD, 2020. https://ghr.nlm.nih.gov/gene/DCX. Accessed August 25, 2020.

67. National Center for Biotechnology Information (NCBI): DCX doublecortin [Homo sapiens (human)]. NCBI, Bethesda, MD, 2020. https://www.ncbi.nlm.nih.gov/gene/1641. Accessed August 25, 2020.

68. Horesh D, Sapir T, Francis F, Wolf SG, Caspi M, Elbaum M, Chelly J and Reiner O: Doublecortin, a stabilizer of microtubules. Hum Mol Genet 8: 1599-1610, 1999.

69. Gleeson JG, Peter TL, Flanagan LA and Walsh CA: Doublecortin is a microtubule-associated protein and is expressed widely by migrating neurons. Neuron 23: 257-271, 1999.

70. Francis F, Koulakoff A, Boucher D, Chafey P, Schaar B, Vinet MC, Friocourt G, McDonnell N, Reiner O, Kahn A, et al: Doublecortin is a developmentally regulated, microtubuleassociated protein expressed in migrating and differentiating neurons. Neuron 23: 247-256, 1999.

71. STRING: DCLK1 protein (human)-STRING coexpression view. https://string-db.org/cgi/network?taskId=bnI9rrwHb9Jm\&sessio nId=bLIMVpiJ6j48. Accessed June 29, 2020. 
72. Koizumi H, Tanaka T and Gleeson JG: Doublecortin-like kinase functions with doublecortin to mediate fiber tract decussation and neuronal migration. Neuron 49: 55-66, 2006.

73. Huttlin EL, Ting L, Bruckner RJ, Gebreab F, Gygi MP, Szpyt J, Tam S, Zarraga G, Colby G, Baltier K, et al: The BioPlex Network: A systematic exploration of the human interactome. Cell 162: 425-440, 2015.

74. Huttlin EL, Bruckner RJ, Paulo JA, Cannon JR, Ting L, Baltier K, Colby G, Gebreab F, Gygi MP, Parzen H, et al: Architecture of the human interactome defines protein communities and disease networks. Nature 545: 505-509, 2017.

75. Slepak TI, Salay LD, Lemmon VP and Bixby JL: Dyrk kinases regulate phosphorylation of doublecortin, cytoskeletal organization, and neuronal morphology. Cytoskeleton (Hoboken) 69: $514-527,2012$

76. National Center for Biotechnology Information (NCBI): ANK2 ankyrin 2 [Homo sapiens (human)]. NCBI, Bethesda, MD, 2020 https://www.ncbi.nlm.nih.gov/gene?cmd=Retrieve\&dopt=full_ report\&list_uids $=287$. Accessed June 29, 2020 .

77. Liu ZQ, He WF, Wu YJ, Zhao SL, Wang L, Ouyang YY and Tang SY: LncRNA SNHG1 promotes EMT process in gastric cancer cells through regulation of the miR-15b/DCLK1/Notch1 axis. BMC Gastroenterol 20: 156, 2020.

78. Meng QB, Yu JC, Kang WM, Ma ZQ, Zhou WX, Li J, Zhou L, Cao ZJ and Tian SB: Expression of doublecortin-like kinase 1 in human gastric cancer and its correlation with prognosis. Zhongguo Yi Xue Ke Xue Yuan Xue Bao 35: 639-644, 2013 (In Chinese).

79. Cao W, Wei W, Zhan Z, Xie D, Xie Y and Xiao Q: Regulation of drug resistance and metastasis of gastric cancer cells via the microRNA647-ANK2 axis. Int J Mol Med 41: 1958-1966, 2018.

80. Cao W, Wei W, Zhan Z, Xie D, Xie Y and Xiao Q: Role of miR-647 in human gastric cancer suppression. Oncol Rep 37: 1401-1411, 2017

81. Girotto G, Vuckovic D, Buniello A, Lorente-Cánovas B Lewis M, Gasparini P and Steel KP: Expression and replication studies to identify new candidate genes involved in normal hearing function. PLoS One 9: e85352, 2014

82. Wells HRR, Newman TA and Williams FMK: Genetics of age-related hearing loss. J Neurosci Res 98: 1698-1704, 2020

83. Vuckovic D: Identification of the genetic determinants of hearing loss by means of genetic isolates. Università degli studi di Trieste, Trieste, 2015. https://www.openstarts.units it/handle/10077/10847. Accessed March 2, 2015.

84. Cancer Genetics Web: MSI1. Gene Summary. http://www. cancerindex.org/geneweb/MSI1.htm. Accessed August 29, 2020

85. Song X, Zhou C, Zhou S, Zhang L, Feng G, Zhao D and Huang F: The expression patterns of Mis1 is related with the glioma grade and the cytoplasmic Mis1 promotes angiogenesis. Tissue Cell 45: 1-6, 2013.

86. Gao C, Han C, Yu Q, Zhou J, Guan Y, Li N, Zhou J, Tian Y and Zhang Y: Downregulation of Msil suppresses the growth of human colon cancer by targeting p21cip1. Int J Oncol 46: 732-740, 2015

87. Moghbeli M, Forghanifard MM, Sadrizadeh A, Mozaffari HM, Golmakani E and Abbaszadegan MR: Role of Msi1 and MAML1 in regulation of notch signaling pathway in patients with esophageal squamous cell carcinoma. J Gastrointest Cancer 46: 365-369, 2015

88. Sureban SM, Qu D and Houchen CW: Regulation of miRNAs by agents targeting the tumor stem cell markers DCLK1, MSI1, LGR5, and BMI1. Curr Pharmacol Rep 1: 217-222, 2015.

89. Sakakibara S, Nakamura Y, Yoshida T, Shibata S, Koike M, Takano H, Ueda S, Uchiyama Y, Noda T and Okano $\mathrm{H}$ : RNA-binding protein Musashi family: Roles for CNS stem cells and a subpopulation of ependymal cells revealed by targeted disruption and antisense ablation. Proc Natl Acad Sci USA 99: 15194-15199, 2002.

90. Kim H, Lee C, Kim WH, Maeng YH and Jang BG. Expression profile of intestinal stem cell markers in colitis-associated carcinogenesis. Sci Rep 7: 6533, 2017.

91. Ye F, Zhou C, Cheng Q, Shen J and Chen H: Stem-cell-abundant proteins Nanog, Nucleostemin and Musashil are highly expressed in malignant cervical epithelial cells. BMC Cancer 8: 108, 2008

92. Sureban SM, May R, Qu D, Asfa S, Anant S and Houchen CW: Knockdown of Musashi-1 Results in Tumor Growth Arrest Through Inhibition of c-MYC, Notch-1 and EMT by Let-7a, Mir-144 and Mir-200a MicroRNAs dependent mechanisms respectively. Gastroenterology 140: S48, 2011.

93. Vo DT, Qiao M, Smith AD, Burns SC, Brenner AJ and Penalva LOF: The oncogenic RNA-binding protein Musashil is regulated by tumor suppressor miRNAs. RNA Biol 8: 817-828, 2011.
94. Kim CK, Yang VW and Bialkowska AB: The role of intestinal stem cells in epithelial regeneration following radiation-induced gut injury. Current Stem Cell Rep 3: 320-332, 2017.

95. GeneMANIA: DCLK1: H. sapiens. https://genemania org/. Accessed September 17, 2020.

96. GeneCards:TNIKGene(Protein Coding).https://www.genecards org/cgi-bin/carddisp.pl?gene=TNIK. Accessed September 17, 2020 .

97. GeneCards: CALM1 Gene (Protein Coding). https://www. genecards.org $/ \mathrm{cgi}$-bin/carddisp.pl?gene=CALM1. Accessed September 17, 2020

98. GeneCards: CDCA8 Gene (Protein Coding). https://www.genecards.org/cgi-bin/carddisp.pl?gene $=$ CDCA8\&keywords $=$ CDCA8 Accessed September 17, 2020.

99. GeneCards: DGUOK Gene (Protein Coding). https://www. genecards.org/cgi-bin/carddisp.pl?gene=DGUOK\&keywords $=$ DGUOK. Accessed September 17, 2020.

100. GeneCards: FBLIM1 Gene (Protein Coding). https://www. genecards.org/cgi-bin/carddisp.pl?gene=FBLIM1\&keywords= FBLIM1. Accessed September 17, 2020.

101. GeneCards: HAX1 Gene (Protein Coding). https://www.genecards.org/cgi-bin/carddisp.pl?gene $=$ HAX1\&keywords=Dclk1 Accessed September 17, 2020.

102. GeneCards: NUFIP1 Gene (Protein Coding). https://www genecards.org/cgi-bin/carddisp.pl?gene=NUFIP1\&keywords $=$ NUFIp1. Accessed September 17, 2020.

103. Weygant N, Qu D, Berry WL, May R, Chandrakesan P, Owen DB, Sureban SM, Ali N, Janknecht R and Houchen CW: Small molecule kinase inhibitor LRRK2-IN-1 demonstrates potent activity against colorectal and pancreatic cancer through inhibition of doublecortin-like kinase 1. Mol Cancer 13: 103, 2014.

104. Yan R, Li J, Zhou Y, Yao L, Sun R, Xu Y, Ge Y and An G: Inhibition of DCLK1 down-regulates PD-L1 expression through Hippo pathway in human pancreatic cancer. Life Sci 241: 117150,2020

105. Lorenzo N, Sabina DM, Guido C, Ilaria Grazia Z, Samira S, Valeria A, Daniele C, Diletta O, Antonella G, Marco M, et al: DCLK1, a putative stem cell marker in human cholangiocarcinoma. Hepatology 73: 144-159, 2021

106. Kumar C, P T V L and Arunachalam A: Structure based pharmacophore study to identify possible natural selective PARP-1 trapper as anti-cancer agent. Comput Biol Chem 80: 314-323, 2019

107. Fu Y, Ye T, Liu YX, Wang J and Ye F: Based on the virtual screening of multiple pharmacophores, docking and molecular dynamics simulation approaches toward the discovery of nove HPPD inhibitors. Int J Mol Sci 21: 5546, 2020.

108. Shiri F, Pirhadi S and Ghasemi JB: Dynamic structure based pharmacophore modeling of the Acetylcholinesterase reveals several potential inhibitors. J Biomol Struct Dyn 37: 1800-1812, 2019.

109. Benafqir M,Hsini A, Laabd M, Laktif T, Ait Addi A, Albourine A and Alem NE: Application of Density Functional Theory computation (DFT) and Process Capability Study for performance evaluation of Orthophosphate removal process using Polyaniline@Hematite-titaniferous sand composite (PANI@ HTS) as a substrate. Sep Purif Technol 236: 116286, 2020

110. Zhao Z, Li E, Qin Y, Liu X, Zou Y, Wu H and Zhu T: Density functional theory (DFT) studies of vanadium-titanium based selective catalytic reduction (SCR) catalysts. J Environ Sci (China) 90: 119-137, 2020

111. Vafaei-Nezhad M, Ghiasi R and Shafiei F: Conformational Analysis of 2-halo-1,3,2-dioxaphosphinanes: A density functional theory (DFT) Investigation. Chem Methodol 4: 161-171, 2020.

112. Schaller D, Sribar D, Noonan T, Deng L, Nguyen TN, Pach S, Machalz, Bermudez M and Wolber G: Next generation 3D pharmacophore modeling. WIREs Comput Mol Sci 10: e1468, 2020

113. Lee JY, Krieger JM, Li H and Bahar I: Pharmmaker: Pharmacophore modeling and hit identification based on druggability simulations. Protein Sci 29: 76-86, 2020.

114. Pal S, Kumar V, Kundu B, Bhattacharya D, Preethy N, Reddy MP and Talukdar A: Ligand-based pharmacophore modeling, virtual screening and molecular docking studies for discovery of potential topoisomerase i inhibitors. Comput Struct Biotechnol J 17: 291-310, 2019.

This work is licensed under a Creative Commons Attribution-NonCommercial-NoDerivatives 4.0 International (CC BY-NC-ND 4.0) License. 